\title{
Zika cases climb to 147 in US and Puerto Rico
}

\author{
Michael McCarthy \\ Seattle
}

A total of 147 cases of Zika virus infection in the United States and Puerto Rico have been reported to the US Centers for Disease Control and Prevention as at 26 February. Of these, 107 occurred in 24 US states and 40 on the island of Puerto Rico.

In a teleconference briefing with reporters, the CDC's director, Tom Frieden, said that all of the 107 cases reported within the US had been travel related but that most of the 40 cases reported in Puerto Rico had been acquired on the island through local transmission. "There is the potential for hundreds of thousands of Zika cases in Puerto Rico," Frieden said.

On 26 February the CDC also reported on the cases of nine pregnant travelers who were infected with the Zika virus while traveling in areas where there is local transmission of the virus: American Samoa, Brazil, El Salvador, Guatemala, Haiti, Honduras, Mexico, Puerto Rico, and Samoa.

The nine women had at least one of the four common symptoms of Zika virus infection-fever, rash, conjunctivitis, or arthralgia - and all reported a rash. Of six women who reported symptoms in the first trimester, two miscarried, two underwent elective pregnancy terminations, one delivered a live born infant with microcephaly, and one continues her pregnancy. Of two women who reported symptoms in the second trimester, one gave birth to an apparently healthy infant and one pregnancy is continuing. One woman who reported symptoms in the third trimester has given birth to a healthy infant.

Frieden told reporters that CDC officials had not expected to see brain abnormalities in such a small case series. Although there was no definitive proof that Zika infection alone was the cause of microcephaly, "the evidence for this is getting stronger by the day," he said. The CDC currently advises women who are pregnant or considering becoming pregnant to avoid travel to areas with active Zika virus infections, but if they do so to take steps to avoid mosquito bites.
A second CDC report described two confirmed and four probable cases of Zika virus infection by sexual transmission in women. ${ }^{2}$ The cases, which were reported 6-22 February, all involved vaginal intercourse without a condom with a male partner who was either symptomatic at the time or had been symptomatic shortly before.

Frieden said that although the health officials had expected that possibly hundreds or even thousands of US citizens might return from Zika affected areas infected by the virus, they had not anticipated so many sexually transmitted cases. The new report underscores the importance of the CDC's recommendation that men who live in or have returned from areas affected by Zika virus use a condom if they have sex with a woman who is pregnant, Frieden said.

To date, all reports of sexual transmission of Zika virus involve cases in women to whom the virus has been transmitted from symptomatic or recently symptomatic male partners. ${ }^{3}$ There have been no reports of transmission from infected women to their sex partners or reports of sexual transmission from people who had asymptomatic Zika virus infections, which may account for up to $80 \%$ of infections.

For all The BMSs latest articles on the Zika virus epidemic go to bmj. co/zika.

Meaney-Delman D, Hills SL, Williams C, et al. Zika virus infection among US pregnant travelers: August 2015-February 2016. MMWR Morb Mortal Wkly Rep 2016-26 doi:10. 15585/mmwr.mm6508e1er.

2 Hills SL, Russell K, Hennessey M, et al. Transmission of Zika virus through sexual contact with travelers to areas of ongoing transmission: continental United States, 2016. MMWR Morb Mortal Wkly Rep 2016;26. doi:10.15585/mmwr.mm6508e2er. .

3 McCarthy M. US health officials investigate sexually transmitted Zika virus infections. BMJ 2016;352:11180.26921165.

Published by the BMJ Publishing Group Limited. For permission to use (where not already granted under a licence) please go to http://group.bmj.com/group/rights-licensing/ permissions 